\title{
A LANGUAGE PLAN FOR PRIMARY SCHOOL TEACHER EDUCATION
}

\author{
Yvonne Barnard \\ Durban College of Education
}

\section{INTRODUCTION}

This paper introduces a different perspective on the grouping of teacher trainees for purposes of language study and reports on the current experimental application of a new first year language curriculum at the Durban College of Education. This language curriculum is designed to

- provide a legitimate and tenable basis for the grouping of students for purposes of language study

accommodate students' particular language needs

address the problem of deficient cognitive academic language proficiency of tertiary students.

Before explaining the structure and implementation of the curriculum, I shall briefly indicate the macrolinguistic perspectives that triggered the attempt to change the existing curriculum dramatically, and elaborate on the linguistic bases on which the design of the new curriculum rests.

\section{CONTEXT OF THE PROBLEM - SOCIOLINGUISTIC RERSPECTIVES}

The first perspective that provides an insight into the problem is a sociolinguistic one which falls within the domain of English as an object of study and has bearing on students' language course selection.

The traditional structure of language curricula at many tertiary institutions seems to rest on an artificial distinction between 
Eirst and second language. This distinction is certainly artificial for those tertiary students in South Africa who are non-mothertongue speakers of English but who have opted for English as a medium of instruction. In such cases students usually also find themselves enrolled in English First Language courses. This is a ridiculous contradiction of terms, unless one assumes that "English First Language" is the name of a specific kind of English course which is highly prestigious and therefore desirable but has nothing to do with mother-tonguedness. Therein lies part of the problem: because of the social stigmatisation of English second Language, pupils and students often opt for a language course which does not accommodate their particular needs.

A twofold solution to this problem would be to do away first with the English First Language/English Second Language distinction in teacher education and have only English - a point that has been suggested by various roleplayers currently involved in primary and secondary school curriculum development. Secondly, the content of English courses would have to be adapted to accommodate the disparate needs of learners who are mother-tongue speakers as well as the needs of non-mother-tongue speakers in a manner that is nonstigmatised. A very different basis for language course distinction is therefore indicated.

The second sociolinguistic perspective is linked to the first one and pertains to English as a medium of instruction in other subjects, often referred to as "mainstream English". Non-mothertongue speakers are expected to function successfully in instructional circumstances which do not accomodate non-mothertongue speakers. According to the NEPI Report (1992:79) existing textbooks used in schools do not take account of second language learners' particular needs. An assumption that the first-year dropout rate must be related to inappropriately written textbooks because students cannot access the texts with suficient comprehension, is taking a superficial view of the problem and 
confusing the attributed cause of the problem with evidence of an underlying problem. Students inability to access decontextualised academic texts and lectures at levels that would ensure study success is evidence of an underlying deficiency. Furthermore, it would be equally incorrect to assume that first-year drop-out rates pertain to second-language speakers only. For many mother-tongue speakers texts and lectures are surprisingly opaque, as was discovered in a questionnaire recently given informally to second year students. I turn to psycholinguistic issues to shed some light on the nature of the problem apparently experienced by unsuccessful students.

\section{PSYCHOLINGUISTIC PERSPECTIVES}

Lack of study success amongst tertiary students in their first year and the concomitant high drop-out rate is too well-known to those involved in tertiary education to require documentary substantiation. Poor success rates in subjects other than languages have only in the last decade and a half been clearly related to the inadequate development of a particular aspect of language proficiency.

Skutnabb-Kangas \& Toukamaa (1976) drew attention to the distinction between a "surface fluency" in language and academically-related aspects of language proficiency. Cummins (1979a) expanded on the distinction between "surface fluency" and "conceptual-Iinguistic knowledge" and later (ibid.1979b) formalised the distinction in terms of basic interpersonal communicative skills (BICS) and cognitive academic language proficiency (CALP) (Cumnins 1984:136). BICS was defined as

the manifestation of language proficiency in everyday communicative contexts (ibid.137),

whereas CALP pertained to the

the manipulation of language in decontextualized academic 
situations (ibid.).

According to Cumnins (1984:136) commuicatively proficient students - that is to say students proficient in day-to-day survival in English - involved in a study programme which uses their second language as a medium of instruction are likely to perform considerably below the performance of their English-speaking peers. O'Malley $(1988: 44,45)$ also reports that various researchers have found that development of academic skills lags behind the development of social communicative skills, "often by as much as five to seven years" (Cummins 1983, 1984). The assumption cannot be made that "surface fluency" (BICS) implies ability to deal with language in decontextualised academic situations. The closelyrelated issue of the apparent CALP deficiencies of first-language speakers requires brief consideration, as this point has direct bearing on the design of the language curriculum proposed in the second part of this paper.

All normal children develop conversational fluency in their mother tongue, but ability to manipulate language in decontextualised academic situations does not follow as a matter of course. Surface manifestations of proficiency are frequently the focus of educators while the aspects of language proficiency that are considerably moxe relevant for students' cognitive and academic progress are neglected (Fig.i) as a result of the mistaken notion that communicative proficiency in informal face-to-face situations is sufficient for study purposes (cf. Cummins 1984:136). The surface and deeper levels of the cognitive and language processes considered to pertain to language proficiency are presented in Fig.i below. This diagram represents the two kinds of proficiency identified as basic interpersonal communicative skills (BICS) and cognitive academic language proficiency (CALP). 
Fig 1 Surface and deeper levels of Language proflciency

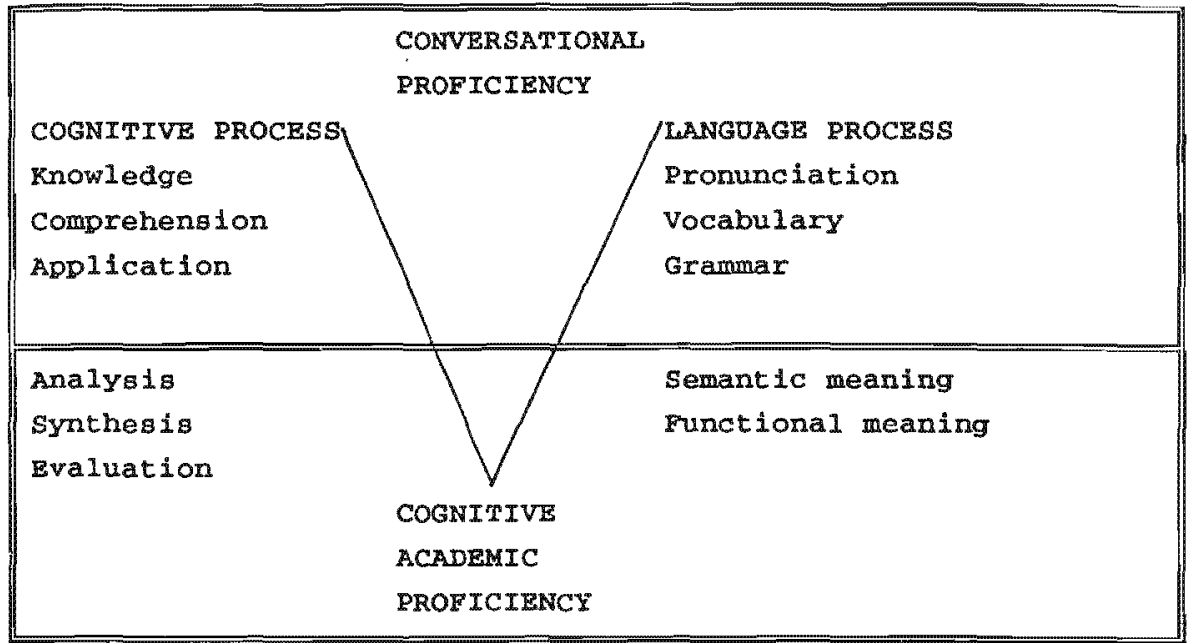

(Cummins 1984:138)

Realising the limiting rigidity of his earlier dichotomous view, Cummins expanded the BICS/CALP dichotomy on two intersecting continua to reflect interactive cognitive and contextual dimensions (Fig. ii).

Fig.ii Interactive cognitive and contextual continua

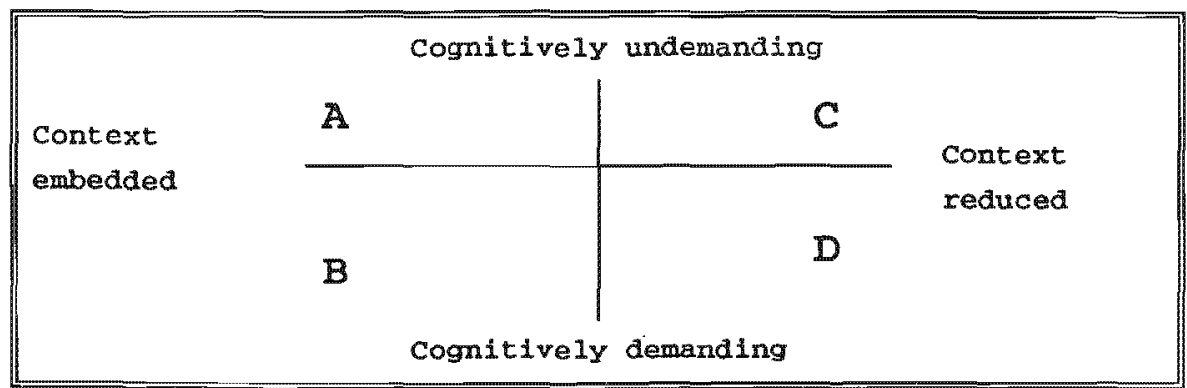

Cummins $1984: 139$

The horizontal continum represents the linguistic qualities of the 
language being accessed and the vertical continuum represents the learner's level of inguistic development. The context- embedded erd of the horizontal continuum represents language that is supported by the contextual clues found in spoken language in informal face to face communication and heavily illustrated children's stories and strip stories with speech bubbles. At the opposite more demaniing end of the language continuum learners have to rely exclusively on the interpretation of linguistic elements in order to understand the message. At tertiary institutions most text books and formal lectures fall within this category.

The cognitively undemanding end of the vertical continuum represents a level of development where language has become fully automatised. The lower end of the continuum represents a level of language engagement that requires conscious attention. This conscious cognitive involvement with linguistic elements is the result of language that has not yet become automatised. Although Cummins developed this model to apply to second language learners. first language learners also occasionally find themselves in language situations that demand attention. According to this view, language that is cognitively demanding requires the cognitive involvement of the learner; attention is then diverted to a Iinguistic task that interferes with comprehension of the content contained in the text. Students who cannot access texts with linguistic ease predictably have a poor study success prognosis.

Working on the assumption that students who reported that they "did not understand the language" were actually saying that they did not understand the content of the message, a course was devised to provide for the development of analytical, synthetic and evaluative cognitive skills through language tasks that focused on semantic and functional meanings. The result of the incorporation of a course designed to address a particular need was the complete remodelling of the structure of the English curriculum to make it possible for students to exercise a choice of course according to 
their particular needs and preferences.

\section{ADPLIED LINGOISTIC PERSPECTIVBS}

Deficient development of cognitive academic language proficiency is not limited to second language speakers; nor are all second language speakers necessarily deficient in this respect. It cannot be disputed that many mother tongue speakers do not have the necessary language proficiency that allows them to survive in decontextualised academic situations, as evidenced by high drop-out rates of first year students for whom their mother-tongue is the medium of instruction at tertiary institutions. If these unsuccessful students had initially complied with the minimum entry requirements of those institutions, it must follow that lack of success cannot be attributed to inadequate general cognitive abilities. In questionnaires and discussions such students at our institution revealed that they "did not understand the language" a comment unexpectedly elicited from first language speakers as well. It was evident that a language course distinction that was based on $\mathrm{L} 1 / \mathrm{L} 2$ differences was not tenable; students required very differently structured courses that were based on their particular level of ability to deal with academic language in cognitively demanding decontextualised situations (quadrant $D$ in Fig.ii). If students were deficient in this respect, they required a language course structured to accomodate this particular need. If they demonstrated adequate levels of cognitive academic language proficiency, they should then be able to deal with a course that demanded this kind of proficiency.

The development of the language curriculum that has emanated from these briefly indicated linguistic insights has taken account only of the particular circumstances and needs of the students at the Durban college of Education. It is to the development of this LANGUAGE PLAN that I now turn. 


\section{THE LANGUAGE PLAN}

A range of tests done at the Durban College of Education over the past eight years suggests that poor scores in literature tests which require that students engage in cognitive processes of analysis, synthesis and evaluation to arrive at semantic and functional meaning may be related to deficient levels of cognitive academic language proficiency. Armed with information pertaining to student performance in tests, examinations and specially designed remedial courses, and informed by the linguistic insights referred to above, the English curriculum was redesigned and restructured to take cognisance of the problems identified. The notion of language course differentiation based on cognitive academic language proficiency racher than an artificial first-language/secondlanguage distinction has subsequently been expanded to encompass the three languages presented at the college: English, Afrikaans and zulu. with particular language-specific adaptations. This expanded structure would enable students to choose any two or three languages, and any one of the two optional components within each of the language curricula, as these optional components are considered equivalent in terms of accepted course criteria for the Senior Primary diploma.

A further development is the consideration of feasible exit points after two years, three years and four years of study. Although the two year exit point is not currently acceptable in terms of the official minimum criteria, the structure is already in place should it be reguired in the future.

The formal proposal of the new LANGUAGE PLAN was in principle accepted by the College Council in 1993, and permission was granted for the experimental implementation of the curriculum for one year. As the Afrikans department has requested to be excluded from the experiment, it is not possible to assess the full impact of the LANGUAGE PLAN across the three languages. Students of Afrikaans are still grouped according to traditional mother-tongue/other tongue 
distinctions. In the zulu department, however, the LANGUAGE PLAN has already been extended to the second year to accommodate particular student needs by making the ZLIT component available.

The rationale of the new curriculum then is informed by three perspectives:

- the cognitive academic language proficiency levels of students

- the constitution of the student body at the college

- the constitution of pupils in primary school classrooms. The language curriculum aims to:

- develop students' general language proficiency

- give students a broad-based understanding and appreciation of literature in general, with particular focus on youth and children's literature

- provide the academic information related to teaching

- develop language teaching skills

- provide the information and skills needed to teach pupils for whom the MOI is not their mother tongue.

- accommodate students who require CALP development

- accommodate students who have a particular flair for iterature.

students, who are not labelled for placement in any particular language course upon entry into the college, have a free choice of any two or three languages. Each language course consists of a compulsory basic component and one optional component. Within each course, students have a choice between two optional components according to their individual needs and preferences. The permutation of these options is a total of 18 possible language course combinations. The only choices previously available to students were to take zulu as an additional language or not. The structure of the languages curriculum and suggested exit points are ilustrated in rable 1 . 
Table 1 STRUCTORE OF LANGOAGES CURRICULUM AND PROPOSED EXIT POINTS

ENGLISH

AFRIKAANS

ZULO

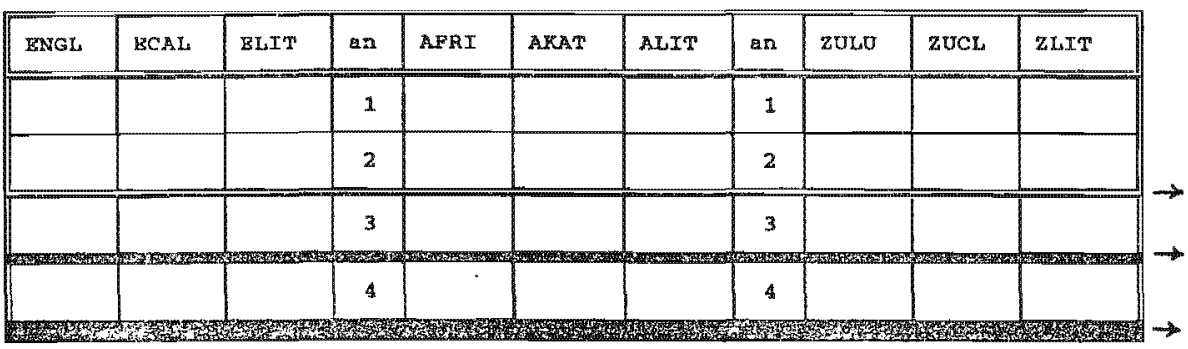

CODES

ENGL

English Basic

ECA.

English Cognitive

Academic Language

ELIT

English Literature
AFRI

Afrikaans Basies

ARA2

Afrikaans Kognitief-

Akademiese Taal

ALIT

Afrikaans Letterkunde
ZULU

Zulu Basic

ZOCL

zulu

Communicative Language

ZLIT

Zulu Literature

The Basic component can be illustrated with reference to the English course (Table 2) even though the subcomponents are not always directly translatable to the other language courses. The classroom-targeted basic component is designed to provide students with the information and skills required to function in the classroom.

In the English course, the introduction to literature subcomponent which includes film and video study is intended to raise students' awareness of visual and verbal signals and symbols, images in the media, stereotyping and literary significance. The reading enrlchment subcomponent - so called to avoid confusion with ELIT, 
the optional literature component - focuses on youth and children's literature and related issues.

Table 2 ENGLISH COURSE STRUCTURE

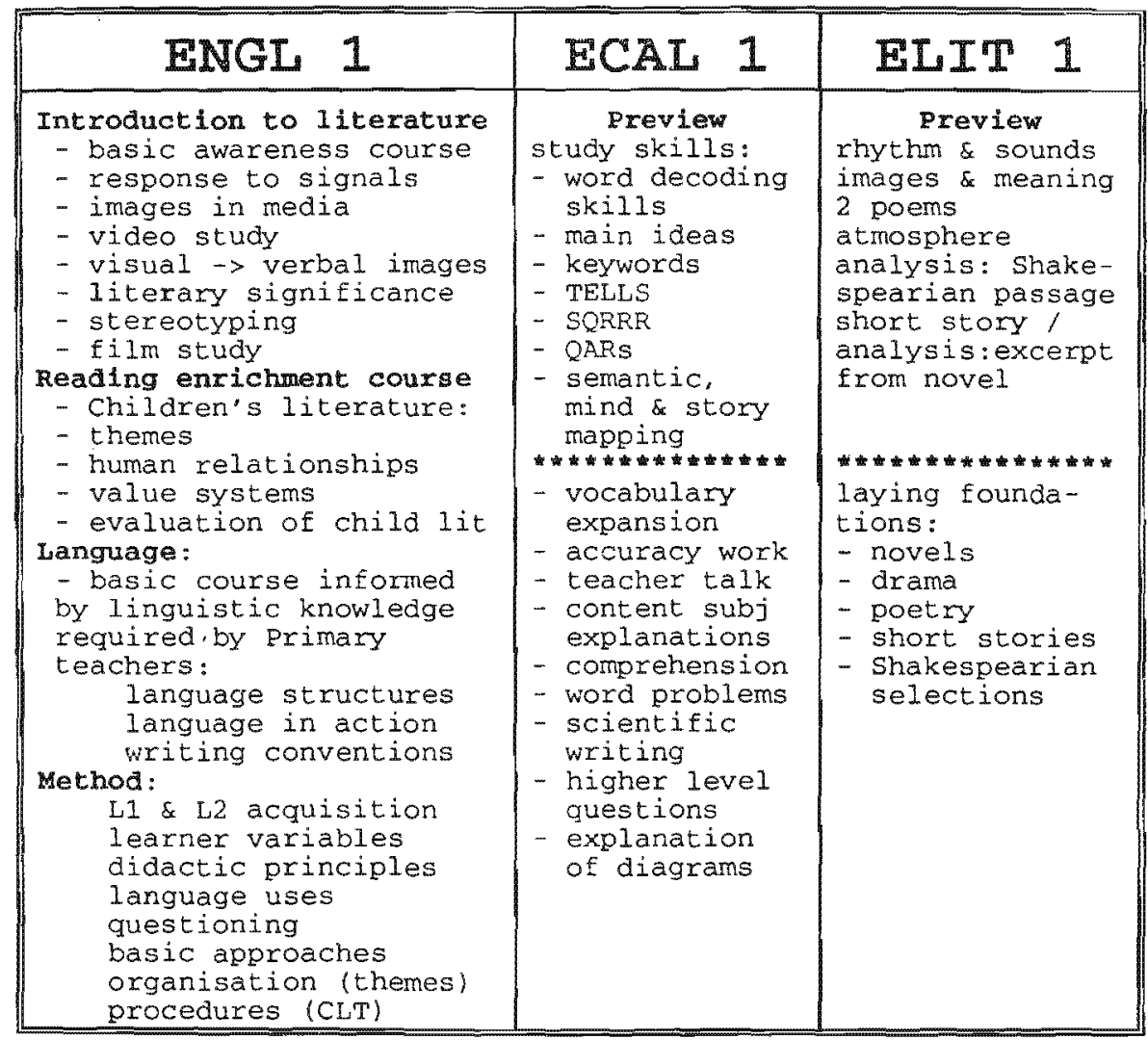

The language subcomponent is designed to provide students with the explicit linguistic information that teachers would need to teach language in a primary school classroom. The method subcomponent provides a theoretical macrolinguistic framework to enhance 
understanding of the didactic principles, methodological approaches and techniques which are the focus of this part of the Basic course. In contrast to the classroom-targeted Basic course, the two optional courses are learner-targeted in that both courses aim to improve individual skills of learners. The English Cognitive Academic Language (BCA. I) and the Afrikaans Rognitief-Akademiese Taal (AKAT) components, as indicated earlier, focus on the development of a particular aspect of lenguage proficiency. Links are established with the Basic component by the use of texts encountered in the Basic component.

The parallel of the ECAL/AKAT component in the zulu course is the zulu Communicative Language (zUCL) component, designed to accommodate beginner learners of zulu. This does not imply that all second language speakers of $\mathrm{zulu}$ would be obliged to take this option; proficient second language speakers of zulu are free to choose the Zulu literature (ZLIT) course. As Zulu is not a medium of instruction in subjects other than zulu at the Durban college of Education, cognitive academic language considerations do not apply to the same extent in zulu as in Afrikaans and English.

Space restrictions do not allow discussion of all aspects of the experimental implementation of the LANGUAGE PLAN. As the structure of the first year English syllabus illustrates the main options available to the students within the proposed LANGUAGE PLAN, the experimental project as it pertains to the English course will be discussed. An interim report on the LANGUAGE PLAN experimental project at the Durban College of Education is presented in the next section.

THE EXPERTMENTAL LAANGDAGE PLAN PROJECT: A PROGRESS REPORT (ENGIiBh course)

objectives

The objectives of the experimental implementation of the LANGUAGE PLAN are to establish whether the proposed structure of the 


\section{LANGUAGE PLAN}

- removed stigmatised course selection bases;

- provided more tenable and legitimate bases for course differentiation;

- enabled students to make a free and informed choice;

- allowed students to choose according to their individual language needs;

- accommodated the need for cognitive academic language development within the differentiated structure:

- increased the selection options available to students.

\section{Test subjects}

The 107 test subjects comprising both sexes are all the first year students who have enrolled in the English course. Sixty-two subjects are mother-tongue speakers of English and 44 are nonmother-tongue speakers of English. One subject is English/ Afrikaans bilingual in the narrow sense of the word.

\section{Generalisability}

As the test group is not representative of the population of first year teacher trainees throughout South Africa, the results are not generalisable to other institutions. This does not mean that certain parallels in similar institutions may not be perceived, but no generalisable claims are made by the researchers. The LANGUAGE PLAN has been designed and developed to accommodate the needs of a particular institution.

\section{Procedures and materials}

A preview course of the ECAL and the ELIT components was presented for five weeks to enable students to make an informed choice when selecting the optional components of the English course. Subjects were provided with ECAL and ELIT study guides at the beginning of the course. The preview course was presented to the subjects, who were divided according to the alphabet inco three equally numbered groups, in five thirty minute sessions per week, 
with 10 sessions used for ECAL and 15 for ELIT. The ECAL sessions were presented alternately by two lecturers, and the ELIT sessions were presented in rotation by four lecturers. This was done to avoid the possibility that the presentational style of one particular lecturer affected the outcome of one of the three groups differently. After four weeks, the preview period was interrupted for one week when all first year students were placed at primary schools for practicum purposes. The fifth week was completed upon the students' return to the campus.

\section{Tegts}

Upon conclusion of the preview course, test subjects wrote two ECAL tests and two ELIT tests of 30 minutes each, spread over four days. The ECAL tests measured identification of main ideas, differentiation between factual and non-factual statements, analytical and categorising skills. The ELIT tests measured interpretation of language nuances, inferencing skills and evaluative responses to texts that demanded of subjects a sophisticated engagement of decontextualised language that required interpretation of linguistic cues only.

\section{Regults}

Scores were not subjected to any statistical tests. Superficial examination of the raw scores reflected in Table 3 shows a fairly normal distribution of ECAL scores, but the ELIT scores indicate a positively skewed distribution which suggests that many subjects experienced difficulty with the ELIT tests.

\section{Summary of ECAL and ELIT raw score distribution:}

$\begin{array}{lll}70 \%-99 \% & \text { ECAL: } 25 \% & \text { ELIT: 5\% } \\ 50 \%-69 \% & \text { ECAL: 55\% } & \text { ELIT: 53\% } \\ 20 \%-498 & \text { ECAL: 20\% } & \text { ELIT: 398 }\end{array}$


Table 3 ECAL AND ELIT RAW SCORES

\begin{tabular}{|c|c|c|c|c|c|c|c|}
\hline & $20-29 \%$ & $30-39 \%$ & $40-49 \%$ & $50-59 \%$ & $60-69 \%$ & $70-79 \%$ & $80-89 \%$ \\
\hline ECAL & 0 & 5 & 16 & 30 & 29 & 22 & 5 \\
\hline RLIT & 12 & 14 & 17 & 29 & 26 & 5 & 0 \\
\hline
\end{tabular}

The choices that subjects made after their results had been given to them were of more interest to the researchers than the actual scores. Subjects indicated their choice on a ballot paper which also reflected their individual ECAL and ELIT scores. To express these findings as concisely as possible, the ECAL/ELIT relationship of the scores attained was reflected in four categories based on two dimensions: a high score and a low score. A high score was considered to be 60 and above, whereas below 60 was regarded as a low score. The possible combinations produced the following categories:

$\begin{array}{ll}1 & \text { low ECAL / low ELIT } \\ 2 & \text { low ECAL / high ELIT } \\ 3 & \text { high ECAL / low ELIT } \\ 4 & \text { high ECAL / high ELIT. }\end{array}$

It was expected that subjects in category 1 would select the ECAL option, those in category 2 the ELIT option, those in category 3 the ECAL option and subjects in category 4 the ELIT option. Our expectations were largely met, with exceptions in categories 1,3 and 4 . Out of the total number of 107,32 subjects selected the ELIT course and 75 the ECAL course. The L1/L2 breakdown of the subjects is included in the summary reflecting subjects' course choices in Table 4 . 
Table 4 course CHorces

\begin{tabular}{|c|c|c|c|c|c|c|c|c|}
\hline \multicolumn{3}{|c|}{ CATEGORIBS } & \multirow{2}{*}{ ECAL } & \multirow{2}{*}{ L1 } & \multirow{2}{*}{ L2 } & \multirow{2}{*}{ BLIT } & \multirow{2}{*}{ L1 } & \multirow{2}{*}{1.2} \\
\hline BCAL & & ST & & & & & & \\
\hline 1 Iow & 1 & low & $\begin{array}{c}40 \\
37 \%\end{array}$ & 11 & 29 & $\begin{array}{c}4 \\
4 \%\end{array}$ & 4 & \\
\hline 2 Iow & 1 & high & & & & $\begin{array}{c}7 \\
7 \%\end{array}$ & 7 & \\
\hline $3 \mathrm{hlgh}$ & 1 & Low & $\begin{array}{r}25 \\
23 \% \\
\end{array}$ & 1.6 & 9 & $\begin{array}{c}3 \\
30 \\
\end{array}$ & 3 & \\
\hline High & 1 & high & $\begin{array}{l}10 \\
9 \%\end{array}$ & 7 & 3 & $\begin{array}{c}18 \\
17 \%\end{array}$ & 18 & \\
\hline
\end{tabular}

\section{Discussion}

The results of the preview tests and the subjects subsequent course selections have demonstrated that a proficiency-based language course differentiation is not only tenable, it is preferable. Of the 63 mother-tongue speakers, 32 selected the ELIT course, and 31 the ECAL course. Of this last group, 6 subjects had a high ELIT mark but indicated that they preferred not to take the literature course. In the traditional dispensation these 31 students would have been enrolled in a course for which they had neither the necessary proficiency nor the inclination. of the total of 75 subjects that elected to do the ECAL course, 3 non-mothertongue.speakers had high ELIT scores but opted for the ECAL course nonetheless. It is possible that the ECAL course may have been perceived as a "soft option."

The unexpected category is number 2. It was expected that a low ECAL score would predict a low ELIT score. Seven subjects, all mother-tongue speakers, had low ECAL but high ELIT scores. A possible explanation is that these subjects had made up their minds about the course that they wanted to take before testing was commenced and therefore only studied the ELIT component. 
The last group that requires some comment is the group of 7 subjects who have opted for the ELIT course despite low ELIT scores. It yet remains to be seen whether the testing done after the preview course has any predictive value.

\section{Problems}

Problems encountered were mainly of a logistical nature. Subjects were confused by the involvement of so many lecturers who presented the same components in rotation. Being new to the campus, they were often unsure of the venues and time was unnecessarily wasted. The preview course generally was too heavily loaded content-wise and consequently too long.

A major weakness of the project design was the fact that the conventional testing procedures used required that subjects studied for the tests. Whether subjects had studied for the tests or not would therefore have a major effect on the outcome. This affected the validity of the tests as the intention had not been to measure subjects diligence or their retention skills. However, this weakness did not render the outcome totally invalid as all lecturers involved reported that most subjects appeared to have prepared well for the tests.

The problems identified are not insurmountable. Logistical problems can be overcome by a chronological modular presentation of subcomponents and the involvement of fewer lecturers. The preview period can be shortened and the content material reduced without sacrificing the objectives of the preview course. Different testing procedures such as task-based tests that do not require prior study would enhance validity.

\section{CONCLUSION}

The preview phase of the experimental project has been concluded and the rest of the project will be carefully monitored until the 
end of the academic year when a final evaluation of the project will be made.

The initial phase of the experimental project has demonstrated that a proficiency-based course differentiation is not only tenable and feasible but highly desirable because it is perceived as a nonstigmatised selection basis and provides access to courses which accomodate students' individual needs and preferences, including the development of cognitive academic language proficiency. The selection basis is furthermore legitimate as it enables students to make a free and informed choice. Because students are giver a choice of course selection and are adequately informed about the options available to them, they are in a position to take ownership of their studies and accept responsibility for their own learning. This augurs well for the Euture. 


\section{BIBLIOGRAPHY}

Cummins, J. 1976 "The influence of bilingualism on cognitive growth: A synthesis of research findings and explanatory hypotheses." In: Working Paper on Bilingualiom, 9:1-43.

Cumins, J. 1979a "Linguistic interdependence and the educational development of bilingual children. "In: Review of Educational Regearch, $49: 222-51$.

Cumins, J. $1979 \mathrm{~b}$ "Cognitive/academic language proficiency, linguistic interdependence, the optimum age and some other matters." Working Iapers on Bilingualism, 19:121-29.

Cumins, J. 1983 "Language proficiency and academic achievement. In: oller, J.W. Jr. (ed) 1983:108-129.

Curmins, J. 1984 Bilingualism and Special gducation: Isgues in Agsessment and Pedagogy. Clevedon: Multilingual Matters.

National Education Policy Investigation 1992 Language: Report of the NEPI Language Research Group. Cape Town: OUP.

Oller, J.W. Jr. (ed) 1983 Issues in tanguage Testing and Research. Rowley, Mass.: Newbury House.

O'Malley, J.M. 1988 "The Cognitive Academic Learning Approach (CALLA)." In: Journal of Multilingual and Multieultural Development, 9,1 \& $2: 43-60$.

Skutnabb-Kangas, T. \& Toukomaa, P. 1976 Teaching Migxant Children" Mother Tongue and Learning the Language of the Host country in the context of the socio-cultural situation of the Migrant Family. Helsinki: The Finnish National Commission for UNESCO. 